\title{
EL DIÁLOGO EN LA LITERATURA POLÍTICA DE MÉXICO, 1808-1832*
}

Reynaldo Sordo**

La cultura política moderna en Occidente nació ligada a la formación de la opinión pública. Emmanuel Kant definió mejor que nadie, en 1784, esta nueva realidad: "Para esta ilustración no se requiere más que una cosa, libertad; y la más inocente entre todas las que llevan ese nombre, a saber: libertad de hacer uso público de su razón íntegramente (...) el uso público de su razón le debe estar permitido a todo el mundo y esto es lo único que puede traer ilustración a los hombres (...). Entiendo por uso público aquel que, en calidad de maestro, se puede hacer de la propia razón ante el gran público del mundo de lectores."

Los ilustrados tenían una gran fe en el uso público de la razón para difundir los nuevos conocimientos, cambiar la sociedad, educar al pueblo ignorante y reformar al poder político. Ellos entendieron también, la utilidad de la palabra escrita para la difusión de las nuevas ideas. José Joaquín Fernández de Lizardi en una polémica con un fraile carmelita, en 1825, da cuenta de la ventaja de la palabra escrita sobre la cultura oral, más propia de la pre-modernidad: "Le apuesto a Fray Manuel de la Expectación (...) a que no tiene bragas para imprimir su sermón

* A la memoria de nuestra querida compañera y amiga Milagros Mier.

** Departamento Académico de Estudios Generales, ITAM.

${ }^{1}$ Emmanuel Kant, “¿Qué es la Ilustración?”, en Filosofía de la Historia,1978, México, FCE, p. 28. 
REYNALDO SORDO

conforme lo predicó (...) y se lo repito a su reverencia, que si ellos tienen púlpitos para insultarme, yo tengo prensas para defenderme, y la ventaja está por mí, porque las palabras se las lleva el viento, y los escritos permanecen. ¡Pobres frailes chaquetas* carmelitas!”.2

En la Nueva España, a partir de 1808-1810, como afirma Rafael Rojas, "se percibe la apertura del discurso político allí donde sólo se verificaba la exposición de temas científicos y filosóficos...”. ${ }^{3}$ Entre estos años y la consumación de la independencia en 1821, el discurso político tendría tres vertientes: la insurgente, la realista constitucional, formada a partir de la Constitución de Cádiz de 1812 y la realista absolutista. Los escritores de las tres vertientes comenzaron a elaborar un discurso político para formar una opinión pública en el sentido de los intereses de la tendencia que favorecían.

La libertad de imprenta fue decretada por las Cortes españolas, el 10 de noviembre de 1810. Este decreto estableció un precedente que sería mantenido, en lo esencial, durante las primeras décadas de nuestra vida independiente. El decreto establecía la libertad de escribir, imprimir y publicar las ideas políticas, sin previa censura, pero bajo ciertas restricciones y responsabilidades. Los autores e impresores serían responsables del abuso en esta libertad. Los libelos infamatorios, los escritos calumniosos, los subversivos de las leyes fundamentales de la monarquía, los licenciosos a la decencia pública y buenas costumbres serían castigados de acuerdo a las leyes. Todos los escritos sobre materias de religión quedaban sujetos a la previa censura de los ordinarios eclesiásticos. El decreto, finalmente, establecía los procedimientos para los juicios de imprenta y las penas correspondientes. ${ }^{4}$

* Chaquetas: sobrenombre de los partidarios del gobierno español.

2 José Joaquín Fernández de Lizardi, "Conversaciones del Payo y el Sacristán”, t. II, diálogo 10, 16 de marzo de 1825, en Obras V, Periódicos, 1973, México, UNAM, p. 370-1.

${ }^{3}$ Rafael Rojas, La escritura de la independencia. El surgimiento de la opinión pública en México, 2003, México, CIDE-Taurus, p. 51.

4 “Decreto de libertad política de la imprenta”, 10 de noviembre de 1810, en Manuel Dublán y José María Lozano, Legislación mexicana o colección 
Como podemos apreciar, la libertad de imprenta, desde su primer establecimiento fue entendida como una libertad limitada y condicionada. Las autoridades virreinales decretaron esta libertad, sólo por un corto espacio de dos meses a partir del 5 de octubre de 1812. Nuevamente, el 15 de abril de 1820, los acontecimientos de España obligaron a poner en vigor el decreto de libertad de prensa de 1810. La explosión de los escritos políticos fue impresionante. Se había abierto un espacio que no volvería a cerrarse sino hasta finales del siglo XIX.

Sin embargo, la frontera entre lo permitido y lo no permitido no fue siempre clara. Las interpretaciones podían ser variadas. Era fácil abusar de la libertad de imprimir las ideas, y también por consiguiente, las autoridades pudieron reprimir a cualquier escrito que consideraran contrario al orden público, la religión, o a la moral y las buenas costumbres.

La libertad de imprenta fue una preocupación central de los políticos a partir de 1820. Ella constituía una condición necesaria para el nuevo orden político. Los diferentes congresos de la época, eran concientes de la importancia de este tema, pero poco hicieron para perfeccionar las leyes de las Cortes de Cádiz. El mayor adelanto en la materia se logró al final del gobierno de Guadalupe Victoria. Una ley, del 14 de octubre de 1828, introdujo los jurados populares para la calificación de los impresos y el juicio de los que se consideraran contrarios a la religión, el orden público, la honra de una persona o la moral y las costumbres. Los jurados para calificar y juzgar un mismo escrito deberían de estar integrados por diferentes ciudadanos. ${ }^{5}$

José María Luis Mora, a finales de la década de los años veinte, pensaba que el abuso en esta materia era un proceso lógico al pasar de los controles del absolutismo a la nueva situación de libertad: "La experiencia que ha ido acreditando cuan perjudiciales son los abusos

completa de las disposiciones legislativas desde la independencia de la República, edición oficial, 1876, 34 vols., México, Imprenta del Comercio, a cargo de Dublán y Lozano, hijos, I, número 77.

5 "Ley.- Se sustituye el título $7^{\circ}$. Del reglamento de imprenta sobre jurados”, en Dublán y Lozano, op. cit., I, número 607. 
REYNALDO SORDO

de la libertad de imprenta, los ha ido también disminuyendo, y los ha de disminuir todavía más, porque la opinión publica se ha ido formando, y los folletos inmorales son vistos con desprecio, no producen utilidad ni honor a sus autores y por lo mismo no se repiten.” ${ }^{6}$ Esta observación aguda del pensador liberal puede comprobarse con facilidad. La década de auge de la literatura política es sin duda la primera posterior a nuestra independencia. También influiría además de la madurez de la opinión pública, el fallecimiento de algunos de los escritores más activos como José Joaquín Fernández de Lizardi (El Pensador mexicano), Pablo Villavicencio (El Payo del Rosario), Luis Espino (Spes in Livo) y Rafael Dávila (La Rata güera). Por otra parte, en el decenio de los años treinta predominarían gobiernos partidarios del orden y las restricciones en los derechos políticos.

La independencia de México, alcanzada en septiembre de 1821, abría la posibilidad del tránsito a la modernidad política: el establecimiento de un estado liberal, fundado en los principios de la soberanía nacional, el sistema representativo popular, la división de poderes y la responsabilidad de los funcionarios públicos. La caída de Iturbide, en abril de 1823, agregaría a los principios del estado liberal, la organización republicana y federal. Según la tesis de Rafael Rojas, a partir de 1824, los actores políticos del México independiente se moverían principalmente en cuatro formas de sociabilidad: los grupos parlamentarios, las corrientes de opinión pública, las logias masónicas y los pronunciamientos militares. ${ }^{7}$ Las corrientes de opinión pública encontraron en la libertad de imprenta con limitaciones, un campo propicio para expresar sus ideas políticas sin previa censura. El título de un impreso de Cádiz de 1811, bien puede reflejar lo sucedido en México a partir de 1820: Diarrea de las imprentas. Memoria sobre la epidemia de este nombre que reina actualmente en Cádiz... ${ }^{8}$

${ }^{6}$ José María Luis Mora, “Libertad de imprenta”, en Obras sueltas, 1963, México, Porrúa, p. 704.

${ }^{7}$ Rojas, op. cit., p. 87-166.

${ }^{8}$ Pedro Recio, 1811, Cádiz, Vda. de Comes. 
Cada posición política pudo conocerse, argumentar, criticar a las autoridades establecidas. El gobierno, constituido tuvo también sus órganos de expresión, en la prensa oficial. Ninguna facción quedó excluida en la opinión publica. Los escritores encontraron dos instrumentos adecuados a la nueva realidad: la prensa periódica y los folletos. Los autores prefirieron el lenguaje directo, cercano al pueblo, pero esto no quiere decir que renunciaran a las argumentaciones teóricas y a la erudición, cuando era necesaria. Los temas respondían a los intereses del día principalmente.

El folleto fue la principal forma de expresión de la época posterior a la independencia. La definición formal de folleto es la siguiente: "Cuadernillo formado al doblar y coser entre dos y cinco hojas de impresos, lo que da al folleto, como máximo, veinte páginas cuando está impreso en folio, cuarenta cuando está impreso en cuarto y ochenta si está impreso en octavo." 9

El folleto político se convirtió en un medio adecuado a los cambios incesantes de la realidad política, a la proliferación de las facciones; facilitaba la polémica, el consumo rápido y la necesidad de informar. ${ }^{10}$ Un autor de la primera mitad del siglo XIX señalaba los alcances del folleto:

A donde el libro no penetra llega el periódico; y a donde el periódico no llega, circula el folleto. Corre, sube la escalera de los palacios, se encarama en las boardillas; entra sin oposición por debajo de las puertas de las chozas, y de las cabañas ahumadas. Tiendas portátiles, talleres, huertas, hogares, veladoras, taburetes, por donde quiera se encuentra. Soldados, aldeanos, ricos, pobres, señores, artesanos, letrados, y no letrados, viejos, jóve-

${ }^{9}$ Lilian Álvarez de Testa, Ilustración, educación e independencia. Las ideas de José Joaquín Fernández de Lizardi, 1994, México, UNAM, p. 155.

${ }^{10}$ Arturo Soberán Mora, "Las armas de la ilustración: folletos, catecismos, cartillas y diccionarios en la construcción del México moderno”, en Laura Suárez, coord.., Empresa y cultura en tinta y papel (1800-1860), 2001, México, Instituto Mora-UNAM, p. 433-4. 
REYNALDO SORDO

nes, hombres y mujeres, de cualquier opinión y estado, lo pasan de mano en mano y lo devoran. En menos de una semana, hojeado, roto, ennegrecido, gastado por el dedo pulgar, ha dado la vuelta. ${ }^{11}$

\section{Diálogos políticos}

Los escritores, de las primeras décadas del siglo XIX mexicano, tuvieron una predilección por el uso del diálogo como género literario, para expresar alguna idea, argumentar una tesis o simplemente informar de algún acontecimiento y tomar una posición al respecto. Varias preguntas surgen al investigador del período: ¿por qué esta fascinación por el diálogo? ¿Los escritores realmente pensaban llegar al pueblo llano, en su mayoría iletrado? ¿El uso deliberado de un lenguaje popular, tenía esa intención o solamente era un recurso literario que les permitía escribir con más desenfado?

Investigaciones recientes, como las de Roger Chartier, nos han abierto pistas para entender la historia de la cultura escrita. Las obras de Chartier han llamado la atención sobre varios puntos esenciales: la importancia de los lectores, las diversas lecturas que se pueden hacer de un texto, la disolución de la aparente dicotomía entre las ideas y los espacios de socialización de las mismas, en un contexto histórico determinado. Para la Europa que transita a la modernidad, entre los siglos XVI y XIX, Chartier destaca la relevancia de los clubes, las tabernas, los cafés, las plazas públicas y los jardines, como lugares de circulación de las ideas y formación de la opinión pública. ${ }^{12}$

El análisis de diversos diálogos políticos de la época, nos llevan a varias conclusiones: los diálogos aparecen en un momento determi-

11 Timon, [Cormenin], El libre de los oradores, 1850, México, Imprenta de Juan N. Navarro, p. 93, citado en Ibid., p. 432.

${ }^{12}$ Cfr. Roger Chartier, Libros, lecturas y lectores en la Edad Moderna, 1993, Madrid, Alianza; Cultura escrita, literatura e historia, 1999, MéxiCO, FCE. 
nado de la historia de nuestro país, de 1808 a 1832, época de crisis, inestabilidad y cambios profundos; ellos responden a los factores que hemos descrito en las páginas anteriores; pueden realizarse varias lecturas de ellos; no surgieron por generación espontánea, sino que en ellos confluyen al menos dos tradiciones: la ilustrada del siglo XVIII y la popular que podemos rastrear desde la literatura popular del Siglo de Oro español. Esta literatura popular tuvo un gran auge en México, a partir de la segunda mitad del siglo XVIII y estuvo presente en la crisis del mundo colonial. Las autoridades virreinales persiguieron un buen número de obras de esta escritura popular: poesía mística, predicación sagrada, canciones, sátiras y teatro religioso. ${ }^{13}$ Los escritores de las primeras décadas del siglo XIX recibieron una influencia de esta literatura perceptible en el uso del lenguaje del pueblo, la sátira, el acercamiento de la escritura a la oralidad, propia de las representaciones teatrales populares o de los sermones, que fueron muy apreciados en el mundo colonial.

Los autores manifiestan la cultura ilustrada no sólo en las ideas que manejan, sino en la forma de argumentar, el carácter pedagógico implícito en los diálogos, le erudición y la referencia a los escritores de la antigüedad clásica. Los diálogos reflejan el espíritu popular en el uso del lenguaje, con la incorporación de modismos, barbarismos, obscenidades o palabras de doble sentido, el gusto por la ironía y la sátira, que puede llegar al insulto, la utilización de mundos imaginarios para referirse a realidades concretas. Por los diálogos desfilan todos los tipos de la sociedad mexicana: caudillos militares, políticos, congresistas, curas, sacristanes, payos*, yorkinos* y escoceses*, serviles*, señoritas de sociedad, mujeres del pueblo, filósofos, maestras y todo un mundo de marginados como los cuchareros*, barberos, tamborileros, traperos, coheteros, maromeros*, prostitutas, aguadores y mecapaleros*, entre muchos otros. ${ }^{14}$

${ }^{13}$ Cfr. Pablo González Casanova, La literatura perseguida en la crisis de la Colonia, 1958, México, El Colegio de México.

${ }^{14}$ Algunas definiciones mínimas de los personajes señalados con asterisco: Payo: campesino, ignorante y rudo. Yorkinos: masones afiliados al rito de 
REYNALDO SORDO

Los diálogos contienen una temática política muy amplia: crítica a las instituciones, principalmente al congreso, discusiones sobre principios como la libertad de imprenta, los privilegios del clero, el sistema federal, la tolerancia religiosa o simplemente conversaciones sobre acontecimientos como el levantamiento de Hidalgo en Dolores, la coronación de Iturbide, el reconocimiento de Inglaterra, las logias masónicas, la expulsión de españoles o la guerra civil de 1832. Los autores con frecuencia recurrían a la imaginación. En este sentido son muy socorridos los diálogos de los muertos o los sueños. En los primeros, personajes importantes ya fallecidos dialogan sobre la situación de México en un momento dado. Generalmente, la crítica es agresiva y los muertos se lamentan por el futuro de México. El recurso del sueño permite imaginar mundos perfectos, muy alejados de la realidad cotidiana. También los autores llegan a imaginar diálogos entre animales, o entre un animal y un ser humano.

Fernández de Lizardi escribió unos diálogos deliciosos entre los gatos Barbilucio y Machucho o entre los perros Scipión y Berganza. Pero sobre todo, a mí en lo particular me gusta una publicación periódica en forma de diálogo: El hermano del perico que cantaba la victoria. Esta publicación tuvo seis números. Lo singular de este perico es que era pitagórico. El alma del filósofo griego llegó al perico después de un largo viaje. El Pensador mexicano lo compró por cuatro pesos en el mercado. Lo llevó a su casa y toda la familia se enamoró de él. Varios días después, estando el Pensador y el perico solos, este último comenzó a conversar para asombro del escritor:

York. Escoceses: masones afiliados al rito escocés. Serviles: partidarios del despotismo. Cuchareros: ladrones de casas; se les llamaba así por ser los cubiertos de plata uno de los principales objetivos de sus robos. Maromeros: término con un doble sentido, el de cirquero y el de una persona que cambiaba con facilidad de filiación política. Mecapalero: cargadores que usaban el mecapal, faja de cuero con dos cuerdas en los extremos de que se servían los indios para llevar una carga a cuestas, poniendo la faja de cuero en la frente y pasando las cuerdas por debajo de la carga. 
Perico pitagórico -A mí, por el contrario, me tocó en suerte el alma de un filósofo viejo y experimentado, que así ha variado cuerpos en el mundo como varían los cómicos trajes en las representaciones.

El espíritu de este filósofo que me anima, ha animado cuerpos de reyes, de ministros, de magistrados, de jueces, de generales, de damas y de clérigos, de frailes, de ladrones, de usureros, escribanos, médicos, boticarios y toda clase de personas; hasta que por haberse portado mal en el cuerpo de un escritor que lo hizo charlatán, fue sentenciado por Plutón a servir a un perico cual yo soy.

Pensador -iMalo periquito! -le dije-. Eso me huele a metempsicosis a transmigración de las almas o, lo que es lo mismo, a un error fabuloso y grosero, y estoy, por lo mismo, por no creerte... ${ }^{15}$

El Pensador soslaya el problema de la metempsicosis y comienza a dialogar con el perico pitagórico. Este se encuentra ansioso por conocer la realidad política de México. El diálogo se escribió cuando el Segundo Congreso Constituyente estaba formando la Constitución federal. Los números 5 y 6 los dedicó Lizardi a dialogar sobre el sistema federal, tomando como pretexto el discurso del diputado Becerra que se oponía al federalismo. El perico pitagórico dio una cátedra de teoría política a favor del federalismo. ${ }^{16}$

Una característica significativa de los diálogos, y en general, de los folletos de la época, fue la de buscar siempre al contrario. Estas obras no estaban escritas desde la serenidad del análisis objetivo, sino que casi siempre tomaban posturas irreductibles y buscaban el debate, se solazan en él, esperan la réplica del escritor adversario o ellos mismos

15 José Joaquín Fernández de Lizardi, “El hermano del perico que cantaba la victoria”, número 1, 1823, México, Imprenta de Mariano Ontiveros, en Obras V, op. cit., p. 29.

${ }^{16}$ Ibid., números 5 y 6, p. 60-73. 
REYNALDO SORDO

ya son una respuesta a un discurso anterior. En este sentido, el diálogo al interior del discurso no es socrático, ni tolerante, ni abierto, ni busca la verdad, sino la presentación de una idea preconcebida. El diálogo al exterior del discurso tampoco es un verdadero diálogo constructivo, sino que termina por descalificar al que piensa de diferente manera.

José María Luis Mora captó con agudeza esta situación de la literatura política del periodo. Por su interés, a pesar de su extensión, transcribo las ideas de Mora:

De eso [lenguaje inmoderado en los debates] resulta el hábito de replicar siempre y de hacer interminables y fastidiosas las disputas en la sustancia y en el modo, repitiendo lo que se ha dicho y haciendo remisiones a lo primero que se escribió; se fatiga al lector que tiene que ir y venir muchas veces del escrito a la impugnación, de éste a la apología, de aquí a la réplica y de allí volver al primer escrito. Cuando la materia ha sido agotada, como sucede frecuentemente desde el principio de la cuestión, ésta empieza a desnaturalizarse, fijándose en las proposiciones incidentes, extrañas por lo general al asunto principal; entonces acaba la razón, si acaso la hubo al principio y empiezan las injurias; salen a la plaza los defectos personales de cada uno, verdaderos o supuestos; se juzga el escrito, no por lo que es en sí mismo, sino por las cualidades buenas o malas que tiene o se le suponen a su autor y se acaba prodigándose los contendientes todos los dicterios con que la gente soez ha enriquecido el idioma... ${ }^{17}$

Los escritores políticos, de las primeras décadas del siglo XIX mexicano, abarcarían una gama muy amplia de posiciones en la forma de construir el discurso en diálogo. Desde el predominio de la cultura ilustrada hasta la presencia dominante de la cultura popular tradicional.

17 "Sobre la conducta de los escritores respecto de los que impugnan sus producciones”, en Obras sueltas, op. cit., p. 753. 
EL DIÁLOGO EN LA LITERATURA

Todos los matices se pueden encontrar en las posturas intermedias. Finalmente, quisiera mostrar tres ejemplos de esta escritura política: dos en los extremos y una en el justo medio.

\section{El diálogo desde el poder}

José Mariano Beristáin de Souza (1756-1817), una vez que estalló la revolución de 1810, fue una de los escritores más adversos al movimiento insurgente. El canónigo Beristáin fue un criollo de vasta cultura que ha pasado a la historia de las letras mexicanas por su Biblioteca hispanoamericana septentrional. D. José Mariano recibió muchas distinciones del gobierno español y se convirtió en uno de sus principales apologistas. ${ }^{18}$ El levantamiento del cura Hidalgo movió a Beristáin a escribir quince diálogos para condenar el movimiento, tratando de formar una opinión pública favorable a la unidad del virreinato y a la obediencia a sus autoridades. Los diálogos fueron escritos a finales de 1810 y principios de 1811.

El autor quiso darle un carácter popular a su obra, pero no logró alcanzar este propósito. Lo popular suena artificioso en todo momento. Los personajes no tienen vida. El lenguaje y las argumentaciones son académicas. La erudición sepulta cualquier intento de naturalidad en el diálogo. Sin embargo, no deja de ser interesante el esfuerzo deliberado por acercarse a un sector de la sociedad muy alejado del mundo del autor. En la mayoría de los diálogos aparecen tres personajes: Filopatro, Aceraio y Morós. El personaje principal es Filopatro, un hombre sabio y patriota que conduce el diálogo y tiene las principales intervenciones. Aceraio hace segunda al primero y sus opiniones van en el mismo sentido y de alguna manera representa el buen sentido común del pueblo. Morós es el necio inoportuno, no deseado, amante de la como-

${ }^{18}$ Cfr. Francisco Sosa, Biografías de mexicanos distinguidos, 1985, México, Porrúa, p. 86-8; Antología del centenario, 1935-1985, México, UNAM, p. 75-8. 
REYNALDO SORDO

didad y la buena vida. Morós es el pretexto para corregir el punto de vista equivocado. Morós no habla con malicia, pero es un necio que no reflexiona, habla sin ton ni son, y, sin proponérselo, fomenta la discordia. ${ }^{19}$

Desde el primer diálogo, Beristáin arremete contra el cura Hidalgo:

Aceraio -Vamos al otro Jefe, El Doctor Hidalgo.

Filopatro - ¡Qué Doctor ni qué calabaza!...No ha criado la universidad de México monstruos de esa clase.

Aceraio -Así le llaman. En fin un hombre de sesenta años, criado siempre en el ocio y el regalo.

Filopatro -Déjate de pinturas: no descubras lo que para el caso es lo mismo. Fijémonos únicamente en que es un Sacerdote y un Párroco. ¡Dios inmortal! Un ministro del Santuario, cuyo oficio era ofrecer la hostia inmaculada y pacífica, se ve hoy al mando de una tropa sanguinaria... ${ }^{20}$

Los diálogos manejan ideas muy interesantes, desde el punto de vista del gobierno virreinal: acabar con las distinciones de criollo y gachupín, ya que ambos son españoles; mostrar que los indios fueron engañados por los líderes, contribuir con la madre patria amenazada por la insurrección; y, difundir ideas de respeto a las leyes y a las autoridades civiles y religiosas. Pero sobre todo, los diálogos insisten en no dejarse llevar por chismes, rumores vagos o noticias falsas que afectaran el orden establecido. Beristáin es consciente de una nueva realidad: la aparición de la opinión pública. ${ }^{21}$

19 J.M. Beristáin, “Diálogo tercero”, en J.E. Hernández y Dávalos, Historia de la Guerra de Independencia de México, 1878, México, José María Sandoval impresor, II, p. 695-739.

Los nombres de los personajes tienen ya un carga en el significado, para dirigir el diálogo: Filopatro: amor a la patria. Aceraio: incisivo, mordaz, penetrante. Morós: flojo, lento, incumplido.

${ }^{20}$ Ibid., II, p. 696.

${ }^{21}$ Ibid., II, p. 695-739. 
La lucha comenzada en 1810, también se convertiría en una guerra de discursos y de símbolos. Filopatro, en el diálogo número siete enseña a Morós y Aceraio pruebas irrefutables de la relación del cura Hidalgo, con un enviado de Napoleón, el general francés Dalmivar: una minuta cifrada en francés y una estampa que le acompaña:

Fil. -Decís bien. Pero aquí está otro documento, que acompaña a esa Minuta. ¿Qué os parece?

Mor. -Aquí veo un Águila pintada, que quiere despedazar a un León. ¡Ah! Esa es la Águila de Napoleón que quiere destrozar al León de España.

Fil. -Es algo peor.

Acer. - ¿Peor?

Fil. -Sí. Porque lo que dice Morós es cosa antigua, ya sabida: que no nos debía ahora de causar admiración; pues hemos visto que la Águila francesa ha declarado la guerra al León de España. Acer. -¿Pues que cosa peor significa o representa esa estampa? Fil. -Leed lo que dice ese letrero.

Acer. -¡Jesús me valga!

Mor. -¿Qué os ha sucedido? ¿Os ha mordido el Águila, u os ha arañado el León?

Acer. -¡Tal maldad, Dios soberano! ¡Es Águila Mejicana queriendo despedazar al generoso León de España! ¡A su defensor y bienhechor! ¡A su Padre amoroso! ¡ A su tierno hermano! Mor. - ¿Es posible que esa Águila no es francesa, sino la americana?

Fil. -Así dice el letrero... ${ }^{22}$

En los últimos diálogos, después de la derrota de Hidalgo en la batalla de Aculco, Beristáin predice el fin de los insurgentes y desarrolla la idea de cooperar a la salvación de la patria. Morós dice que la patria somos todos, y cuidando cada uno lo suyo ésta se salvaría.

${ }^{22}$ Ibid., II, p. 713. 
REYNALDO SORDO

Filopatro replica definiendo la patria como una comunidad ordenada al bien común. Por lo tanto, un buen patriota debe contribuir, no sólo moral, sino económicamente. Beristáin preparaba de esta manera a la opinión pública, para los préstamos forzosos y contribuciones extraordinarias, que se volvieron prácticas comunes del gobierno español, en los años posteriores a 1810 .

\section{El diálogo baja al pueblo}

Un escritor característico de la época surgió a partir de la libertad de imprenta, decretada en 1820, teniendo aproximadamente una década de vigencia: el panfletista político. Rafael Rojas lo define con precisión:

Escritores vulgares que por lo general no habían rebasado la instrucción media y que, a través de una educación autodidacta, adquirían una abigarrada y caprichosa cultura, ajena y contrapuesta a la que transmitían las instituciones académicas. Los unía enunciados políticos básicos como la defensa a ultranza de la libertad de expresión, el anticlericalismo absoluto, el antifanatismo relativo, el nacionalismo desespañolizador y el jacobinismo antiaristocrático. Pero los separaban las pasiones personalizadas y la condición marginal que los privaba de toda solidaridad posible. ${ }^{23}$

Estos escritores formaban parte de las clientelas de algún político; estaban cerca del pueblo y tenían capacidad de movilizarlo. Los líderes políticos los utilizaban, pero los dejaban en el mundo marginal en que vivían. ${ }^{24}$ Los panfletistas eran rechazados por todos los grupos, se les consideraba un peligro para el orden público, la religión y la moral. El

${ }^{23}$ Op. cit., p. 168-9.

${ }^{24}$ Ibid., p. 167-195; Héctor R. Olea, El payo del Rosario. Escritor liberal del siglo XIX. (Pablo Villavicencio 1796-1832), 1963, México, Sociedad de Amigos del Libro Mexicano, p. 98-103. 
panfleto tenía poder de penetración entre las diversas clases sociales. Se voceaba en las calles y era leído lo mismo en las pulquerías, que en los lugares donde acudía la gente decente. Este alcance del panfleto permitía a los políticos formar una opinión favorable a las decisiones del poder. Por otra parte, los escritores de libelos estuvieron siempre en conflicto con las autoridades civiles y religiosas. Con facilidad incurrían en delitos contra la libertad de imprenta. Los panfletistas visitaban la cárcel con cierta frecuencia. Por esta razón, ellos se constituyeron en los principales defensores de la libertad de imprenta. En este sentido, estos escritores agresivos, descuidados en la escritura, obscenos e irreverentes cumplieron una función de traducción de los discursos de las elites políticas a las masas ignorantes. ${ }^{25}$

Rafael Dávila fue uno de los panfletistas más irreverentes de la época. El comenzó su actividad de escritor en 1820, escribiendo un papel que lo llevó a la cárcel: La verdad amarga, pero es preciso decirla. Después de la independencia fue contrario a Iturbide, se opuso a su coronación e intentó formar una revolución en las galerías del congreso movilizando a cuatrocientas personas. Su acción abortó y estuvo a punto de perder la vida. Posteriormente fue favorable a los yorkinos, aunque después fue perseguido por el gobierno yorkino de Vicente Guerrero. Dávila afirmaba que cinco veces lo intentaron asesinar los esbirros de este general. Durante el gobierno de Anastasio Bustamante, Dávila escribió a sueldo del gabinete de Lucas Alamán.

Rafael Dávila se movía como pez en el agua escribiendo en forma de diálogo. El escritor publicó dos periódicos en este género literario: Taller de cohetería. Diálogos críticos-alegóricos entre un cohetero y un tamborilero ${ }^{26}$ y El Toro. Diálogos crítico-jocoserios entre un cohetero y un tamborilero. El primero fue una publicación semanal entre 1827 y 1828 . El segundo tuvo una frecuencia semanal en 1829 y bise-

\footnotetext{
${ }^{25}$ Rojas, op. cit., p. 167-195.

${ }^{26}$ 1827, México, Imprenta de la Ex-Inquisición, a cargo de Manuel Ximeno, $\mathrm{n}^{\circ} 1$; Publicaciones periódicas mexicanas del siglo XIX, 1822-1855, 2000, México, UNAM, p. 423-5 y 432-5.
} 
REYNALDO SORDO

manal entre 1829 y 1832. El autor consideraba a las dos publicaciones como una sola obra. Los personajes de ambos diálogos son los mismos: un cohetero y un tamborilero (Cuajo Largo).

En el primer número de los diálogos, Rafael Dávila expuso sus intenciones al escribir y el porqué de la forma que adoptó:

En cuanto al estilo y dialecto de este periódico diré, que me he querido acomodar al lenguaje del pueblo, y este no entiende cuando los discursos están llenos de la elocuencia y la retórica... Yo no sé otra cosa que decir verdades, y como ésta mientras mas desnuda más hermosa, las digo sin rodeos y sin disfraces: a unos les gusta, a otros no, no puedo escribir a gusto de todos. Algunas palabras suenan mal, y sin embargo unos las festejan con grandes risas, y otros arrugan las narices: yo quiero advertir a unos y a otros, que hablo sin malicia, y que si ellos son maliciosos y dan interpretación mala a las palabras, ellos tienen la culpa... ${ }^{27}$

En el diálogo cuarto, el cohetero y el tamborilero conversan sobre 64 los españoles, en una época en la que aumentaba la hispanofobia en el país:

Tamb. -Este cuadro si está muy lucido: ¡cuántos jefes y oficiales! Estos serán los jefes americanos, ¿no señor?

Cohet. -Ellos son, y van a cumplimentar al presidente.

Tamb. -Pero señor ¿por qué tienen aquellos jefes principales una zeta en la frente?

Cohet. -Para denotar que son españoles que abrazaron nuestra causa.

Tamb. -¡Jesús señor! Si casi todos los jefes son españoles: pues ¿qué no hay americanos ameritados que puedan servir estas plazas?

${ }^{27}$ Dávila, op. cit., p. 3-7. 
Cohet. -Sí, pero estos tomaron partido en la independencia. Tamb. -Y los americanos mucho antes.

Cohet. -Sí, pero estos ya eran jefes.

Tamb. -Jefes había entre americanos antiguos.

Cohet. -Sí, pero estos son aplicados.

Tamb. -Y muy hábiles los hay de los llamados insurgentes.

Cohet. -Sí, pero son por lo común desidiosos.

Tamb. -Pero para haber peleado contra estos antes de la independencia y mantenido la causa de la patria no fueron desidiosos.

Cohet. -Sí, pero la política,...la... ${ }^{28}$

En este ejemplo, Dávila se mantiene mesurado y correcto en el uso del lenguaje y sobre todo utiliza la ironía para expresar su rechazo a los españoles. En agosto de 1827, un fraile azotó a un muchacho que fue a confesarse con él. El suceso causó un escándalo en la ciudad de México. Dávila aprovechó el acontecimiento para escribir un diálogo irreverente y obsceno que fue motivo de una denuncia del cura de la Santa Veracruz, Dr. José María Aguirre. Los jueces calificaron de sedicioso en tercer grado este impreso, el 18 de septiembre de 1827 y lo condenaron a dos años de prisión en las costas. El castigo, al parecer, no se cumplió en su totalidad, pero hubo un lapso de cuatro meses en el que se dejó de publicar el periódico, lo cuál hace suponer una posible permanencia del autor en la cárcel. A continuación presento un fragmento del escandaloso diálogo:

Cohet. - Te has alargado mucho, sigue con el monte parnaso. Tamb. -Pues veremos este cochino que sigue ¡Qué gordote está! Y su letrero dice abstinencia: le estiro el mecatito que tiene en el ombligo y ...vaya con mil santos: un fraile fernandino se nos ha aparecido con una disciplina en la mano y un dedo en la boca: quien con muchachos se acuesta sucio amanece:

${ }^{28}$ Ibid., Diálogo cuarto, 27 de enero de 1827, p. 46-7. 
REYNALDO SORDO

señor ¿'es este padre el que azotó el otro día al muchacho que fue a confesarse con él?

Cohet. -Es el mismo y lo he puesto ahí para que siquiera ese castigo tenga, porque es regular que no se le chiste una palabra sobre el particular.

Tamb. - ¿Y no se sabe cual fue la causa o motivo de los azotes?

Cohet. -Nada se dice sobre eso, y yo lo ignoro.

Tamb. -Sabed Ud. Señor, yo creo una cosa: como esos padres están tan encerrados, están...pues tan encerrados y tienen muchas...pues muchas. ¿Cómo me explicaré? Pues, así... y por eso haría al muchacho quitarse los calzones para recrearse en sus nalgas con los azotes, porque yo he oído decir que los azotes a unos los mortifica y a otros les da gusto, y el padre creería que el muchacho sería uno de los segundos... ${ }^{29}$

\section{El diálogo espontáneo}

El escritor mexicano más importante en el tránsito de la Colonia al 66 México independiente fue sin duda, José Joaquín Fernández de Lizardi (1776-1827). Lizardi fue periodista político, costumbrista, novelista, poeta lírico y dramático. El primer periódico de Fernández de Lizardi fue una hoja semanal llamada El Pensador mexicano, nombre mismo que adoptó como seudónimo para firmar sus obras. La actividad literaria del Pensador comenzó en 1812 y siguió de manera continuada hasta su muerte, en 1827. Lizardi fue un novelista eminente. Su novela El Periquillo sarniento es considerada la primera novela importante de nuestro país. ${ }^{30}$

Una de las facetas más interesantes de este autor fue la del periodismo político. Sus periódicos y folletos no dejaron de publicarse durante

${ }^{29}$ Ibid., Diálogo veintisiete, 18 de agosto de 1827, p. 156-7.

${ }^{30}$ Luis G. Urbina, “Estudio preliminar”, en Antología del Centenario, op. cit., p. XV-CLXXV. 
estos años, formando un acervo inabarcable. Lizardi fue un producto del liberalismo gaditano. Un ilustrado de pies a cabeza. En el centro de todo su discurso estaba siempre el problema de la educación del pueblo. El Pensador mexicano tenía una fe ciega en el poder de la educación para consolidar la independencia, fomentar el espíritu público y erradicar los vicios de la sociedad mexicana. ${ }^{31}$

Como nadie, Fernández de Lizardi manejó el género del diálogo y supo equilibrar el espíritu ilustrado con las formas tradicionales de expresión. Luis G. Urbina comenta:

Su estilo es llano hasta la chabacanería; su tendencia a la observación y a la imagen naturalistas, lo lleva ser exacto hasta la grosería. Los diálogos, que el maneja con magistral soltura, están copiados con tanta propiedad, que el léxico usado en ellos se halla pletórico de modismos y vocablos regionales...Se trata, en cierto modo, de un folklorista espontáneo, que hizo de refranes, locuciones y giros populares, una literatura especial, genuina y característica, tan apropiada a las circunstancias, que ninguna otra supo encontrar el camino para llegar más pronto al alma de la muchedumbre... ${ }^{32}$

El Pensador usaba la ironía con gran maestría. Mientras sus adversarios escribían con pasión, se enardecían, despotricaban, él permanecía ecuánime. Raras veces utilizaba el insulto violento. “A cuanto pudo alcanzar su delicadeza, fue, el autor del Periquillo, un fino ironista. Hubo momentos en que todos alrededor suyo blasfemaban y gritaban, y él sonreía." 33

Desde el primer número de El Pensador mexicano, del año de 1812, aparece un diálogo sobre la libertad de imprenta entre un impresor y su autor:

${ }^{31}$ Lilian Álvarez, op. cit., p. 157-198.

${ }^{32}$ Urbina, op. cit., p. XCIV-XCV.

${ }^{33}$ Ibid., p. XCVI. 
REYNALDO SORDO

Aut. -¿¿ué tenemos de papeles?

Imp. -Vea Ud. la cuenta, trescientos ejemplares mandó imprimir, se vendieron doscientos: existen sesenta y tres, se llevó Ud. cuatro y se repartieron treinta y tres.

Aut. - ¿Cómo es eso de, se repartieron treinta y tres?

Imp. -Así, veinte y dos a la Audiencia: cuatro a la Intendencia: tres a la Inquisición y cuatro al Arzobispado, son treinta y tres. Aut. -De milagro no mandó Ud. quince al Protomedicato, veinte al Consulado, doce a la Minería, diez a las madres capuchinas, ocho al Hospicio de pobres, y repartió los que quedaban entre los trinitarios y cargadores de la Aduana. ¡Voto ha!... ${ }^{34}$

Con ironía, el Pensador criticaba la costumbre de repartir ejemplares a diversas autoridades coloniales, con lo que los autores tenían una pérdida económica significativa.

Además del sinnúmero de diálogos que escribió Lizardi sobre los mas diversos temas y acontecimientos del momento, destacan varias publicaciones periódicas en forma de diálogo: El hermano del perico que cantaba la victoria citado anteriormente y Las conversaciones del payo y el sacristán, publicadas en 1824 y 1825. Esta obra está dividida en dos tomos. El primero consta de veinticinco números que aparecieron con cierta regularidad, cada tres o cuatro días. El tomo II consta de veinticinco números más dos alcances a los números diecinueve y veintiuno. No existió regularidad en la aparición de los números del segundo tomo. ${ }^{35}$

La publicación apareció en una época precisa. México terminaba por constituirse como una republica federal, después del fallido intento de la monarquía moderada de Iturbide. El 4 de octubre de 1824 fue

${ }^{34}$ José Joaquín Fernández de Lizardi, El Pensador mexicano, t. I, n ${ }^{\circ}$, 1812, México, Imprenta de Doña María Fernández de Jáuregui, reproducción facsimilar, 1987, México, Centro de Estudios de Historia de Condumex.

35 José Joaquín Fernández de Lizardi, “Conversaciones del payo y el sacristán”, en Obras $V$, México, UNAM. 
sancionada la Constitución federal en medio del regocijo universal y grandes expectativas para el país. Al iniciarse 1825 comenzaría a funcionar el sistema federal con toda su complejidad institucional. Frente a la euforia universal, destaca el pesimismo del Pensador. Si bien, los diálogos examinan diversos problemas surgidos en esos días, hay temas recurrentes que preocupan al escritor: la reforma de la Iglesia, la amenaza de una reconquista española apoyada por la Santa Alianza, la libertad de expresión y la inseguridad pública.

En los diálogos participan principalmente un payo y su compadre el sacristán, pero también aparecen Rosita, hija del payo, y el propio Pensador. Los diálogos abordan un tema muy espinoso: la reforma de la Iglesia católica. Los personajes conversan sobre la tolerancia religiosa, los privilegios del clero, el fanatismo del obispo de Sonora y la infalibilidad del Papa.

En la conversación veintiuno del tomo segundo, el payo y el sacristán dialogan sobre la reforma eclesiástica que habían establecido al redactar una constitución imaginaria en diálogos anteriores. La conversación giraría en torno a la obediencia al Papa, ya que este último no había reconocido la independencia de las naciones americanas:

Payo -Bien, yo quedo en esta parte satisfecho, pero estoy tamañito al considerar que el Papa no quiere reconocer nuestra Independencia.

Sacr. -La respuesta es muy fácil y sencilla, y es: conservar la religión católica y no obedecer al Papa.

Payo -¡Jesús mil veces, compadre! ¡Jesús! Esa sí es herejía evidente. ¿Cómo es eso de no obedecer al Papa?

Sacr. -En lo notoriamente injusto no debemos obedecerle. Payo -Pues yo pienso que sí; porque el Catecismo del padre Ripalda dice que debemos al Papa entera obediencia, y eso de entera quiere decir que en todo.

Sacr. -Como de esos disparates dice el Catecismo del padre Ripalda; y así su dicho nada prueba... 
REYNALDO SORDO

Payo -Pero, compadre, yo me admiro cómo los papas llegaron a tan alto poder sobre los reyes, siendo así que en los principios fueron unos súbditos de los emperadores y tanto que necesitaban, después de su elección la confirmación de éstos a costa de un tributo pecuniario.

Sacr. -Me reservo decirle a usted en la conversación venidera lo que se sobre esto; y por ahora le digo que la ignorancia y fanatismo de los príncipes cristianos fue la causa de que los pontífices de Roma desplegaran toda su ambición... ${ }^{36}$

El Pensador no dio tregua al alto clero. El diálogo entre un coronel y un canónigo tiene una ironía más destructora que el veneno de los libelos de Dávila:

Canónigo -Es gana: este maldito Pensador es más hereje que Calvino. Frita me tiene el alma.

Coronel -¿¿Y por qué señor prebendado? ¿ Cuáles son las herejías del Pensador?

Canónigo -¿Qué mayores herejías quiere usted que estampe, que querer que suprima el gobierno las canonjías o a lo menos que nos moderen las rentas?

Coronel -iOh! Esas no son herejías. Ello está muy puesto en razón; porque, padre mío, hablemos con la verdad. ¿De qué sirven los canónigos al Estado? Ellos dicen misas si quieren, jamás confiesan, predican cuando están para ello y vale el sermón buena propina; $y$ al través de esta santa ociosidad estiran la renta por miles, amén de los aniversarios, que no valen poco, y cate usted que sostienen casas magníficas, mesas abundantes y exquisitas, coches maqueados* y todo cuanto necesita para mantener al hombre en regalo.”37

${ }^{36}$ Ibid., II, Conversación veintiuno, p. 475-9.

* Barnizados con goma laca o equivalente, es decir, coches muy limpios, elegantes, de lujo.

${ }^{37}$ Ibid., I, Conversación 13, p. 169. 
No tenemos espacio para mostrar la riqueza de autores, temas y maneras de expresión de esta literatura, ilustrada y popular, en forma de diálogo. Ella floreció por un corto tiempo en nuestro país, en el tránsito del Antiguo Régimen a la modernidad política. Ella fue funcional y sirvió de puente entre las reducidas elites del país y las clases pobres marginadas, principalmente en el espacio urbano de la ciudad de México. Ella dejó de existir en el tercer decenio del siglo XIX. Sin embargo, esta literatura cumplió la función de traducir el lenguaje de los poderosos en términos comunes y corrientes, y, en sentido inverso las demandas de las masas marginadas hacia quienes ejercían el poder en todas sus manifestaciones. Todas las posiciones políticas echaron mano de ella y también guardaron su distancia. Como en todas las épocas, el buen trigo ha permanecido en la memoria colectiva de este país, la mala yerba ha sido sepultada en el olvido. 
